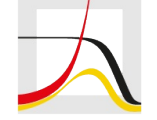

MAX PLANCK INSTITUTE

FOR DEMOGRAPHIC RESEARCH

Konrad-Zuse-Strasse 1 · D-18057 Rostock · Germany · Tel +49 (0) 3812081 - 0 · Fax +49 (0) 3812081 - $202 \cdot$ www.demogr.mpg.de

MPIDR Working Paper WP 2021-004 I March 2021

Revised April 2021

https://doi.org/10.4054/MPIDR-WP-2021-004

\title{
Calculation of week-specific
} age-standardized death rates

from STMF data on mortality

by broad age intervals

\section{Ilya Klimkin}

Vladimir M. Shkolnikov I shkolnikov@demogr.mpg.de

Dmitri A. Jdanov I jdanov@demogr.mpg.de 


\title{
Calculation of week-specific age-standardized death rates from STM F data on mortality by broad age intervals
}

\author{
M PIDR Working Paper \\ Ilya Klimkin¹, Vladimir M. Shkolnikov ${ }^{1,2}$, Dmitri A. Jdanov ${ }^{1,2}$ \\ ${ }^{1}$ National Research University Higher School of Economics, M oscow (Russia) \\ 2 Max Planck Institute for Demographic Research, Rostock (Germany)
}

\section{Abstract}

The Short-Term M ortality Fluctuations (STMF) data series provides an opportunity for analysis of intra-annual excess mortality, in particular, human losses due to the COVID-19 pandemic. Nevertheless, the STM F has a limitation caused by the nature of the collected original weekly death counts. In many countries, weekly death counts are available only by broad age groups or/and are too small and shaky. M oreover, the original age scales somewhat vary by country. Thus, the STM F data file presents weekly deaths and death rates by broad age intervals. This simplifies the usage of the STMF and helps to conduct analyses but limits the comparability of results across countries and time. The comparisons may be biased due to differences between the population age composition. This study addresses the problem by providing a method for the estimation of week-specific standardized death rates (SDRs) that combines the aggregated weekly mortality data with detailed annual data on mortality and population. This allows deriving annual transition coefficients for the transformation of crude death rates into SDRs. We show that the derived SDRs approximate well exact SDRs across time and countries.

\section{Background}

The Short-Term M ortality Fluctuations data series (STMF) is a newly established part of the Human M ortality Database (www.mortality.org) that provides data on deaths and crude death rates (CDRs) by week for all ages combined and five broad age groups 0-14, 15-64, 65-74, 75-84, and 85+. Although STM F data allows analysis of seasonal mortality differences, intra-annual mortality excess, and human losses due to death, direct comparisons between countries and across time may be biased by variations in the population age compositions. Age-independent mortality indicators like standardized death rate or life expectancy by weeks, months, or quarters can not be directly calculated because of the lack of detailed age-specific data. This is especially important when the age-structure differences between populations being compared are substantial. For example, comparisons of the intra-annual mortality excess between the early 2000 s and the late 2010s or between countries with "older" and "younger" populations (e.g. Italy vs. Poland) are especially problematic.

This paper proposes calculation procedures for the estimation of week-specific standardized death rates (SDRs) using broad age groups available in the STMF. 


\section{STM F data and adjustment for consistency with the core HM D}

The STM F provides information on deaths and death rates for all ages combined and the five aggregated age groups by country/region, sex, year, and week. Importantly, STM F provides also input data containing deaths as they were originally published by national statistical offices or other data providers. Table 1 summarizes the STM F data over the period 2000 to 2020 (as of December 15, 2020). In total, the data by 5 -year age groups are available for 30 out of 38 populations. A set of eight countries without detailed data by age (Australia, Canada, England and Wales, Germany, Israel, New Zealand, South Korea, and the USA) includes three large national populations that importantly contribute to the worldwide burden of excess mortality.

Each year in the STM F refers to 52 or 53 weeks. These are standardized weeks with 7 days in each of them according to ISO 8601-2004 guidelines (J danov et al. 2020). Consequently, the first week of some calendar years includes several days (and, respectively, deaths) from the previous year and/or the last week of some years includes several days of the following year, with the implication that a statistical year in the STM F might slightly differ from the respective calendar year and cover a slightly different number of deaths compared to the core HMD or the national statistics. Besides, the weekly data is based on the current registration of vital events and may slightly differ from the final annual statistical reports on population mortality. Thus, the annual sums of weekly deaths may somewhat differ from the annual death counts.

For our further elaborations and also for a general consistency between STM $F$ and HMD, we adjust the STM F weekly deaths in every age group (either 5-year or aggregated) using the core HM D as a "golden standard":

$$
\begin{aligned}
& \widetilde{D}_{y, w, x}^{S T M F}=D_{y, w, x}^{S T M F} \cdot \sum_{w=1}^{N} \frac{D_{y, w, x}^{S T M F}}{D_{y, x}}, \\
& \widetilde{D}_{y, w, i}^{S T M F}=D_{y, w, i}^{S T M F} \cdot \sum_{w=1}^{N} \frac{D_{y, w, i}^{S T M F}}{D_{y, i}},
\end{aligned}
$$

where indices $y, w, x$, and $i$ denote year, week, five year age group, and aggregate age group, respectively, $\mathrm{N}$ denotes the number of weeks, and $D^{\text {STMF }}$ and $\mathrm{D}$ stand for the numbers of deaths in the STMF and HMD core, respectively.

Equations (1a) and (1b) apply to the years in which HM D data is available. Table 1 indicates, however, that for 2020 and a few previous years this data is unavailable in all or many countries. In these years, we use the adjustment factors $\sum_{w=1}^{N}\left(D_{y, w, x}^{S T M F} / D_{y, x}\right)$ and $\sum_{w=1}^{N}\left(D_{y, w, i}^{S T M F} / D_{y, i}\right)$ from the last year for which the HM D data is available.

To compensate for the absence of detailed annual data in the most recent years, we had predicted 5year-age-specific annual death rates using HM D data starting from 2005 to the last available year with the Lee-Carter projection model (Jdanov et al. 2020; Lee, Carter 1992). 
Table 1. Summary of STMF data in 2000-2020 as of 15.12.2020

\begin{tabular}{|c|c|c|c|c|c|c|c|}
\hline $\mathrm{N}$ & Country & $\begin{array}{l}\text { First available } \\
\text { year in the } \\
\text { STM F }\end{array}$ & $\begin{array}{l}\text { Last available } \\
\text { year in the } \\
\text { STM F }\end{array}$ & $\begin{array}{l}\text { Years, } \\
\text { total }\end{array}$ & $\begin{array}{l}\text { Weeks, } \\
\text { total }\end{array}$ & $\begin{array}{l}\text { 5-year ages } \\
\text { available in } \\
\text { STM F }\end{array}$ & $\begin{array}{c}\text { Last available } \\
\text { year in the } \\
\text { HMD }\end{array}$ \\
\hline 1 & Australia & 2015 & 2020 & 6 & 294 & No & 2018 \\
\hline 2 & Austria & 2000 & 2020 & 21 & 1085 & Yes & 2017 \\
\hline 3 & Belgium & 2000 & 2020 & 21 & 1087 & Yes & 2018 \\
\hline 4 & Bulgaria & 2010 & 2020 & 11 & 568 & Yes & 2017 \\
\hline 5 & Canada & 2010 & 2020 & 11 & 558 & No & 2018 \\
\hline 6 & Chile & 2016 & 2020 & 5 & 256 & Yes & 2017 \\
\hline 7 & Croatia & 2000 & 2020 & 21 & 1032 & Yes & 2018 \\
\hline 8 & Czechia & 2005 & 2020 & 16 & 824 & Yes & 2018 \\
\hline 9 & Denmark & 2007 & 2020 & 14 & 724 & Yes & 2019 \\
\hline 10 & England and Wales & 2010 & 2020 & 11 & 568 & No & 2018 \\
\hline 11 & Estonia & 2000 & 2020 & 21 & 1088 & Yes & 2017 \\
\hline 12 & Finland & 2000 & 2020 & 21 & 1087 & Yes & 2019 \\
\hline 13 & France & 2000 & 2020 & 21 & 1087 & Yes & 2018 \\
\hline 14 & Germany & 2016 & 2020 & 5 & 253 & No & 2017 \\
\hline 15 & Greece & 2016 & 2020 & 5 & 251 & Yes & 2017 \\
\hline 16 & Hungary & 2000 & 2020 & 21 & 1085 & Yes & 2017 \\
\hline 17 & Israel & 2000 & 2020 & 21 & 1085 & No & 2016 \\
\hline 18 & Italy & 2015 & 2020 & 6 & 299 & Yes & 2017 \\
\hline 19 & Latvia & 2000 & 2020 & 21 & 1089 & Yes & 2017 \\
\hline 20 & Lithuania & 2000 & 2020 & 21 & 1087 & Yes & 2019 \\
\hline 21 & Netherlands & 2000 & 2020 & 21 & 1086 & Yes & 2018 \\
\hline 22 & New Zealand & 2010 & 2020 & 11 & 515 & No & 2019 \\
\hline 23 & Northern Ireland & 2015 & 2020 & 6 & 307 & Yes & 2018 \\
\hline 24 & Norway & 2000 & 2020 & 21 & 1087 & Yes & 2018 \\
\hline 25 & Poland & 2000 & 2020 & 21 & 1084 & Yes & 2018 \\
\hline 26 & Portugal & 2000 & 2020 & 21 & 1087 & Yes & 2018 \\
\hline 27 & Russia & 2000 & 2019 & 20 & 1040 & Yes & 2018 \\
\hline 28 & Scotland & 2000 & 2020 & 21 & 1088 & Yes & 2018 \\
\hline 29 & Slovakia & 2000 & 2020 & 21 & 1084 & Yes & 2017 \\
\hline 30 & Slovenia & 2000 & 2020 & 21 & 1087 & Yes & 2017 \\
\hline 31 & South Korea & 2010 & 2020 & 11 & 560 & No & 2018 \\
\hline 32 & Spain & 2000 & 2020 & 21 & 1087 & Yes & 2018 \\
\hline 33 & Sweden & 2000 & 2020 & 21 & 1087 & Yes & 2019 \\
\hline 34 & Switzerland & 2000 & 2020 & 21 & 1087 & Yes & 2018 \\
\hline 35 & Taiwan & 2000 & 2020 & 21 & 1079 & Yes & 2014 \\
\hline 36 & USA & 2015 & 2020 & 6 & 410 & No & 2018 \\
\hline 37 & Iceland & 2000 & 2020 & 21 & 1088 & Yes & 2018 \\
\hline \multirow[t]{4}{*}{38} & Luxembourg & 2000 & 2020 & 21 & 1089 & Yes & 2019 \\
\hline & TOTAL, all countries & 2000 & 2020 & 627 & 32359 & Yor $N$ & 2019 \\
\hline & $\begin{array}{l}\text { TOTAL, w/o Iceland \& } \\
\text { Luxembourg }\end{array}$ & 2000 & 2020 & 585 & 30182 & Yor N & 2019 \\
\hline & $\begin{array}{l}\text { TOTAL, w/o lceland \& } \\
\text { Luxembourg, with 5-yr ages }\end{array}$ & 2000 & 2020 & 503 & 25939 & $\mathrm{Y}$ & 2019 \\
\hline
\end{tabular}




\section{Crude death rates and two versions of standardized death rates}

The precise SDRs by year and week is to be computed from the data that contains detailed age-specific death rates $M_{y, w, x}^{S T M F}$ by 5-year age-groups:

$$
S D R_{y, w}=\sum_{x}\left(p_{x}^{S} M_{y, w, x}^{S T M F}\right),
$$

where $p_{x}^{S}$ is the standard population weight for the 5-year age group $x$. We use the European population standard 2013 (Revision of the European Standard Population 2013) with age groups $0-4,5-9, \ldots$ up to the last open-ended age $90+$. The week-age-specific death rates $M_{y, w, x}^{S T M F}$ are calculated as follows

$$
M_{y, w, x}^{S T M F}=\frac{\widetilde{D} S T M, w}{E_{y, x} / N},
$$

if week-specific death counts are available at the required level of details. Following the STM F approach, we use yearly population exposures $E_{x, y}$ divided by the number of weeks $N$. Instead of original weekly death counts $D_{y, w, x}^{S T M F}$ we use the adjusted weekly deaths $\widetilde{D}_{\mathcal{y}, \boldsymbol{w}, x}^{S T M F}$ (according to equations (1a) and (1b)).

Equation (2) determines exact weekly SDRs. Their calculation depends on the availability of weekly data by 5 -year age groups. If the detailed weekly data is unavailable, one may straightforwardly calculate SDR 0 for all ages combined as a weighted average of five $C D R$ s (age groups $0-14,15-64,65-74,75-84$, and 85+):

$$
S D R 0_{y, w}=\sum_{i=1}^{5}\left(p_{i}^{S} C D R_{y, w, i}^{S T M F}\right),
$$

where index $i$ denotes the five aggregate age groups and the standard population weights $p_{i}^{s}$ correspond to the five broad age intervals in the European population standard that are equal to $0.160,0.645,0.105$, 0.065 , and 0.025 , respectively. Nevertheless, the $S D R 0$ has a serious disadvantage. It is based on an assumption that the broad-group-specific values $C D R_{y, w, i}$ do not differ much from the respective weekly $S D R_{y, w, i}$. Only if this assumption holds, the weighting of the $C D R s$ with the standard population weights provides a good approximation of the precise $S D R_{y, w}$ values.

Another idea concerns using an annual ratio of standardized death rate $S D R_{y}$ to crude death rate $C D R_{y}$ for fitting the weekly $S D R_{y, w}$. Thus, instead of the detailed weekly rates $M_{y, w, x}^{S T M F}$, we can use annual 5year-age-specific rates $M_{y, x}$. Correspondingly, formula (2) has to be modified as follows

$$
S D R 1_{y, w}=C D R_{y, w}^{S T M F} \cdot R_{y} ; \quad R_{y}=\frac{\sum_{x}\left(p_{x}^{s} M_{y, x}\right)}{C D R_{y}}
$$

for all ages combined and

$$
S D R 1_{y, w, i}=C D R_{y, w, i}^{S T M F} \cdot R_{y, i} ; R_{y, i}=\frac{\sum_{x \in X_{i}}\left(\rho_{x}^{S} M_{y, x}\right)}{C D R_{y, i}}
$$

In equation (4a), the crude death rate is calculated conventionally $C D R_{y}=\sum_{x}\left(p_{y, x} M_{y, x}\right)$ with the population weights $p_{y, x}$ for year $y$ and age $x$. In equation (4b), $X_{\mathrm{i}}$ denotes a set of 5 -year age intervals belonging to an aggregate age group $i$. For example, the set $X_{1}=\{0,5,10\}$ corresponds to the first 
aggregate age group 0-14. Weight $\rho_{x}^{s}$ is the standard population weight within aggregated age group $i$. It is being calculated as $\rho_{x}^{S}=p_{x}^{S} /\left(\sum_{x \in X_{i}} p_{x}^{S}\right)$. The crude death rate $C D R_{y, i}$ for an aggregated age group $i$ is

$$
C D R_{y, i}=\sum_{x \in X_{i}} \rho_{y, x} M_{y, x} \text { with weights } \rho_{y, x}=p_{y, x} /\left(\sum_{x \in X_{i}} p_{y, x}\right) .
$$

Equations (4a) and (4b) are based on the assumption that week-specific age patterns of mortality do not substantially differ from the annual age pattern.

If for a country in question, annual death rates by detailed ages are not available for one or more years (note HM D data availability in Table 1), one can use for these years predicted age-specific death rates $M_{y, x}^{\text {predict }}$. As we mentioned earlier, these rates were obtained by applying the Lee-Carter projection model (Lee, Carter 1992) to HM D data.

However, the resulting $M_{y, x}^{\text {predict }}$ values may not be precise enough. This is particularly important for the pandemic year 2020. Therefore, we further adjust the predicted death rates by using STM F death rates that are available until the most recent year. The adjustment coefficient for year $y$ and aggregated age group $i$ is

$$
k_{y, i}=\frac{C D R_{y, i}^{S T M F}}{C D R_{y, i}^{\text {predict }}}
$$

with the crude death rates in the numerator and the denominator being

$$
C D R_{y, i}^{S T M F}=\left(\sum_{w} C D R_{y, w, i}\right) / N \text { and } C D R_{y, i}^{\text {predict }}=\sum_{x \in X_{i}}\left(\rho_{y, x} M_{y, x}^{\text {predict }}\right) .
$$

Finally, for countries and years not covered by the HMD, the age-specific death rate at age $x$ such that $x \in$ $X_{i}$, in equations (4a) and (4b) has to be replaced by the adjusted death rate

$$
\widetilde{M}_{y, x}=k_{y, i} \cdot M_{y, x}^{\text {predict }} \text {. }
$$

This way the weekly $S D R 1$ values can be obtained for all countries and years available in the STM F.

Figures 1 and 2 show four types of weekly death rates from the first week of 2000 to the last week of 2020 as well as the ratios of $C D R, S D R 0$, and $S D R 1$ to the exact standardized death rate SDR for Spain and Hungary, respectively.

Both countries experienced sizeable intra-annual fluctuations with pronounced seasonal maximums combined with long-term mortality decline. The difference between $C D R$ and SDR depends on temporal change in the age composition of country populations and in the age patterns of mortality. The $C D R / S D R$ continuously rises due to the progressive population aging. For men, $C D R / S D R$ values are below 1 , for women they are slightly below 1 in the early 2000s and are substantially above 1 in the late 2010s. 

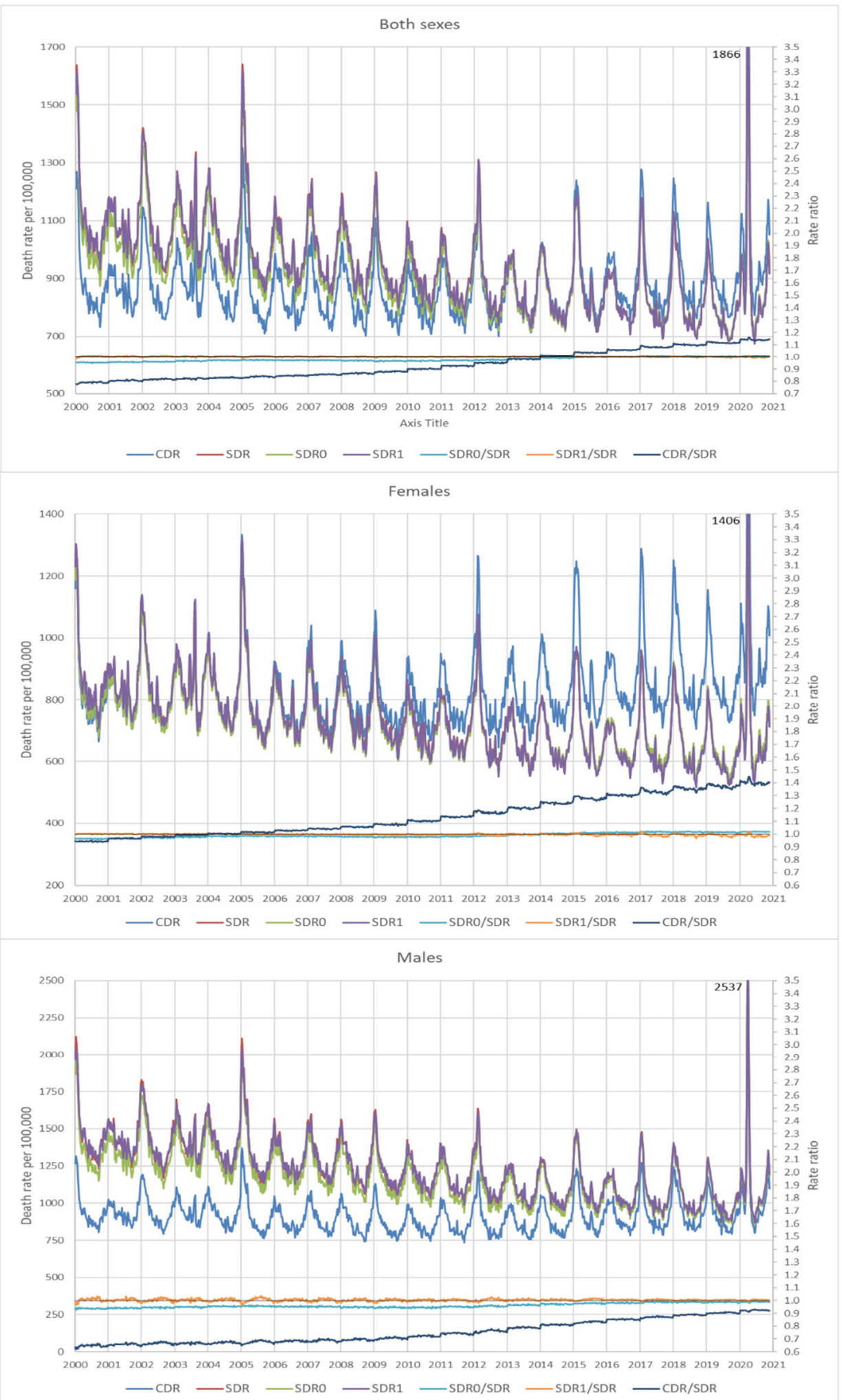

Figure 1. Crude death rate (CDR) and age-standardized death rates SDR, SDR0, and SDR1 per 100000 person-years (left axis) and rate ratios CDR/ SDR, SDRO/ SDR, and SDR1/ SDR (right axis) in Spain in 20002020 , for both sexes, men, and women. 


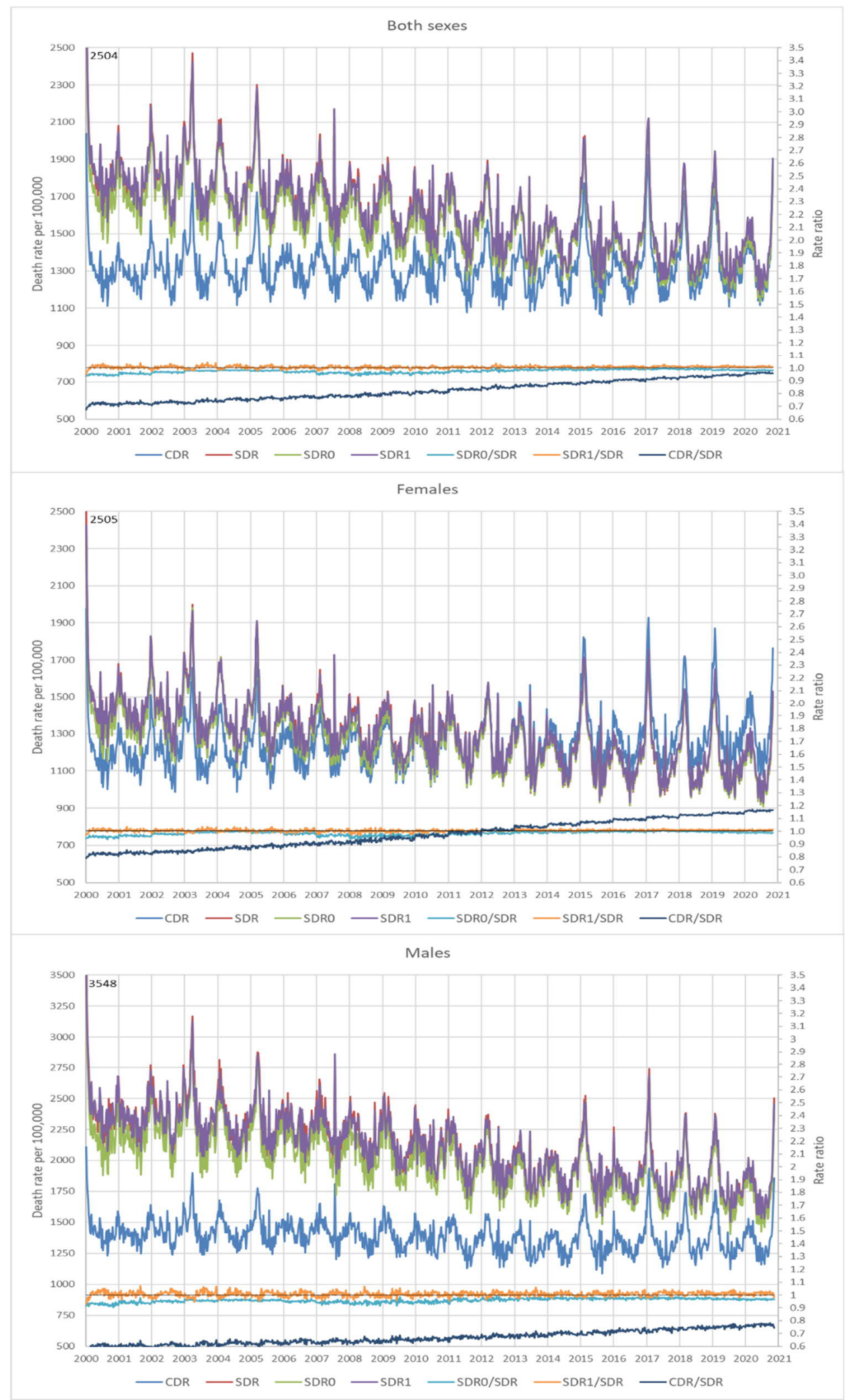

Figure 2. Crude death rate CDR and age-standardized death rates SDR, SDR0, and SDR1 per 100000 person-years (left axis) and rate ratios CDR/ SDR, SDRO/ SDR, and SDR1/ SDR (right axis) in Hungary in 2000-2020, for both sexes, men, and women. 
Figures 1 and 2 suggest that the $S D R 0 / S D R$ ratio somewhat deviates (mostly downward) from 1 . It tends to be more pronounced for men than for women and tends to be larger in the 2000s and the early $2010 \mathrm{~s}$ than in the late $2010 \mathrm{~s}$.

The $S D R 0 / S D R$ ratio lies systematically below 1 . The mean $S D R 0 / S D R$ ratio for males is $4 \%$ in Spain and $4.2 \%$ in Hungary. The maximal downward shifts for males are 7\% in Spain and 10\% in Hungary. The $S D R 1 / S D R$ ratio is not systematically higher or lower than 1 . The mean SDR1/SDR ratio is $0.4 \%$ in Spain and $0.7 \%$ in Hungary. The maximal deviations are $\pm 3 \%$ in Spain and $\pm 7 \%$ in Hungary.

\section{Deviations of SDR1 from SDR. Advantage of SDR1 compared to SDR0}

In this section, we are finding out how well the exact weekly $S D R$ values are approximated by $S D R 0$ and $S D R 1$, which are calculated without the usage of detailed weekly death rates by 5 -year age groups. The examples of Spain and Hungary suggest that deviations of $S D R 1$ from $S D R$ may be quite small and that deviations of $S D R 0$ from $S D R$ are somewhat larger. Table 1 shows that in 30 regions/countries detailed HM D data is available, which allows calculation of $S D R$. Iceland and Luxembourg have very small populations leading to high instability of week-age-specific death rates. After the exclusion of these two countries, the remaining data set consists of 28 countries, 503 years, and 25939 weeks (Table 1). Below, we systematically examine deviations of $S D R 0$ and $S D R 1$ from $S D R$ across countries and weeks in this data.

Table 2 provides country-specific medians, as well as $5^{\text {th }}$ and $95^{\text {th }}$ percentiles of the SDR $1 / S D R$ ratios for all ages combined. The ratios are generally low. The average of country-specific medians (across yearweek combinations) exceeds 1 by $+0.1 \%$ for both sexes, by $-0.03 \%$ for women, and by $+0.5 \%$ for men. $90 \%$ of country-specific median values lie between $-2.7 \%$ and $+2.3 \%$ for both sexes, $-2 \%$ and $+2.4 \%$ for women, and $-3.5 \%$ and $+4.7 \%$ for men. Chile is the only country that lies out of the range with deviations up to $7 \%$ $10 \%$. Information similar to Table 2 for the age ranges $0-14,15-64,65-74,75-84$, and $85+$ is given in Supplementary Annex 1. 
Table 2. The median, 5th, and 95th percentiles of weekly SDR1/ SDRO ratios by sex for 28 countries and all ages combined in 2000-2020

\begin{tabular}{|c|c|c|c|c|c|c|c|c|c|}
\hline \multirow{2}{*}{ Country } & \multicolumn{3}{|c|}{ Both sexes } & \multicolumn{3}{|c|}{ Females } & \multicolumn{3}{|c|}{ Males } \\
\hline & Median & p $5 \%$ & p 95\% & Median & p $5 \%$ & p 95\% & Median & p $5 \%$ & p 95\% \\
\hline Austria & 1.0021 & 0.9894 & 1.0147 & 1.0009 & 0.9848 & 1.0153 & 1.0049 & 0.9737 & 1.0382 \\
\hline Belgium & 1.0013 & 0.9887 & 1.0116 & 0.9981 & 0.9831 & 1.0119 & 1.0065 & 0.9750 & 1.0379 \\
\hline Bulgaria & 1.0070 & 0.9905 & 1.0238 & 1.0087 & 0.9878 & 1.0283 & 1.0055 & 0.9767 & 1.0325 \\
\hline Chile & 1.0547 & 1.0351 & 1.0758 & 1.0894 & 1.0759 & 1.1049 & 1.0236 & 0.9852 & 1.0632 \\
\hline Croatia & 1.0056 & 0.9762 & 1.0336 & 1.0059 & 0.9730 & 1.0353 & 1.0069 & 0.9478 & 1.0651 \\
\hline Czechia & 1.0058 & 0.9828 & 1.0239 & 1.0053 & 0.9830 & 1.0230 & 1.0089 & 0.9708 & 1.0438 \\
\hline Denmark & 0.9977 & 0.9900 & 1.0057 & 0.9936 & 0.9869 & 1.0022 & 1.0045 & 0.9752 & 1.0336 \\
\hline Estonia & 1.0029 & 0.9729 & 1.0319 & 1.0025 & 0.9698 & 1.0339 & 1.0096 & 0.9204 & 1.0916 \\
\hline Finland & 1.0023 & 0.9906 & 1.0162 & 1.0010 & 0.9884 & 1.0139 & 1.0063 & 0.9669 & 1.0496 \\
\hline France & 0.9966 & 0.9831 & 1.0070 & 0.9919 & 0.9720 & 1.0085 & 1.0049 & 0.9833 & 1.0208 \\
\hline Greece & 1.0027 & 0.9944 & 1.0104 & 1.0011 & 0.9878 & 1.0123 & 1.0050 & 0.9984 & 1.0130 \\
\hline Hungary & 1.0065 & 0.9881 & 1.0207 & 1.0072 & 0.9886 & 1.0201 & 1.0082 & 0.9758 & 1.0372 \\
\hline Italy & 0.9986 & 0.9919 & 1.0059 & 0.9948 & 0.9833 & 1.0093 & 1.0051 & 0.9985 & 1.0133 \\
\hline Latvia & 1.0039 & 0.9758 & 1.0279 & 1.0034 & 0.9751 & 1.0307 & 1.0058 & 0.9409 & 1.0749 \\
\hline Lithuania & 1.0050 & 0.9773 & 1.0261 & 1.0054 & 0.9777 & 1.0295 & 1.0028 & 0.9503 & 1.0558 \\
\hline Netherlands & 1.0028 & 0.9881 & 1.0138 & 0.9992 & 0.9930 & 1.0060 & 1.0112 & 0.9684 & 1.0400 \\
\hline Northern Ireland & 0.9981 & 0.9866 & 1.0127 & 0.9941 & 0.9831 & 1.0056 & 1.0057 & 0.9611 & 1.0519 \\
\hline Norway & 0.9997 & 0.9905 & 1.0115 & 0.9969 & 0.9808 & 1.0158 & 1.0059 & 0.9779 & 1.0339 \\
\hline Poland & 1.0037 & 0.9849 & 1.0186 & 1.0033 & 0.9886 & 1.0157 & 1.0058 & 0.9714 & 1.0323 \\
\hline Portugal & 1.0008 & 0.9901 & 1.0157 & 0.9989 & 0.9877 & 1.0109 & 1.0064 & 0.9749 & 1.0375 \\
\hline Russia & 1.0015 & 0.9781 & 1.0192 & 1.0011 & 0.9838 & 1.0131 & 1.0011 & 0.9628 & 1.0320 \\
\hline Scotland & 1.0001 & 0.9897 & 1.0096 & 0.9975 & 0.9898 & 1.0046 & 1.0060 & 0.9725 & 1.0371 \\
\hline Slovakia & 1.0054 & 0.9781 & 1.0320 & 1.0060 & 0.9743 & 1.0335 & 1.0059 & 0.9578 & 1.0609 \\
\hline Slovenia & 1.0043 & 0.9667 & 1.0374 & 1.0035 & 0.9693 & 1.0345 & 1.0086 & 0.9219 & 1.0971 \\
\hline Spain & 0.9992 & 0.9929 & 1.0063 & 0.9968 & 0.9852 & 1.0041 & 1.0043 & 0.9884 & 1.0190 \\
\hline Sweden & 0.9996 & 0.9942 & 1.0067 & 0.9964 & 0.9842 & 1.0093 & 1.0063 & 0.9885 & 1.0235 \\
\hline Switzerland & 0.9998 & 0.9915 & 1.0078 & 0.9965 & 0.9849 & 1.0080 & 1.0071 & 0.9759 & 1.0329 \\
\hline Taiwan & 0.9976 & 0.9780 & 1.0247 & 0.9961 & 0.9740 & 1.0273 & 0.9989 & 0.9730 & 1.0311 \\
\hline Total & 1.0013 & 0.9840 & 1.0230 & 0.9997 & 0.9809 & 1.0240 & 1.0058 & 0.9653 & 1.0473 \\
\hline
\end{tabular}

The relative absolute-value deviations of $S D R 0$ and $S D R 1$ from $S D R$ are be defined as

$$
\begin{aligned}
& D E V 0_{y, w}=\frac{\left|S D R_{y, w}-S D R 0_{y, w}\right|}{S D R_{y, w}} \cdot 100 \%, \\
& D E V 1_{y, w}=\frac{\left|S D R_{y, w}-S D R 1_{y, w}\right|}{S D R_{y, w}} \cdot 100 \% .
\end{aligned}
$$

Comparison of $D E V 1$ and $D E V 0$ reveals the advantage of $S D R 1$ compared to $S D R 2$. Across all year-weekcountry combinations, the average $D E V 1$ values are about twice lower than the average $D E V 0$ values: $1.03 \%$ vs. $2.51 \%$ for both sexes, $1.23 \%$ vs. $1.93 \%$ for women, and $1.57 \%$ vs. $4.04 \%$ for men. Table 3 
compares the medians and $90^{\text {th }}$ percentiles of the $D E V 1$ and the $D E V 0$ distributions and also suggests the advantage of $S D R 1$.

Table 3. Medians and $90^{\text {th }}$ percentiles for the relative deviations DEVI and DEVO by sex for 28 countries in 2000-2020, all ages combined. (in \%)

\begin{tabular}{cccc}
\hline \multicolumn{2}{c}{$D E V 0$} & \multicolumn{2}{c}{$D E V 1$} \\
Median & $\mathrm{p} \mathrm{90 \%}$ & Median & $\mathrm{p} \mathrm{90 \%}$ \\
\hline $\begin{array}{c}\text { Both sexes } \\
1.04\end{array}$ & 2.51 & 0.47 & 1.44 \\
$\begin{array}{c}\text { Females } \\
0.89\end{array}$ & 2.55 & 0.71 & 1.90 \\
$\begin{array}{c}\text { Males } \\
2.66\end{array}$ & 4.66 & 1.08 & 3.27 \\
\hline
\end{tabular}

Finally, Table 4 presents OLS regression that links $D E V 1$ to sex and aggregate age group. The deviation values for men and women exceed the both-sexes reference by $0.2 \%$ and $0.6 \%$, respectively. The deviations for age groups $0-14$ and $85+$ are higher than the all-ages reference by $1.9 \%$ and $0.6 \%$, respectively. On the contrary, the deviations for age groups $15-64,65-74$, and $75-84$ tend to be smaller than the all-ages reference by about -0.7 to $-0.9 \%$.

Table 4. OLS relationship between the absolute-value deviation DEVI with sex and aggregate age group for 28 countries over the period 2000-2020 (in \%)

\begin{tabular}{lrrr}
$\begin{array}{l}\text { Independent } \\
\text { variable }\end{array}$ & $\begin{array}{r}\text { Regr. } \\
\text { coef. }\end{array}$ & $\begin{array}{r}95 \% \mathrm{Cl} \\
\text { Low }\end{array}$ & $\begin{array}{r}95 \% \mathrm{Cl} \\
\text { High }\end{array}$ \\
\hline Sex & & & \\
- both & 0 (Ref) & & \\
- female & 0.220 & 0.208 & 0.232 \\
- male & 0.560 & 0.548 & 0.572 \\
Age group & & & \\
- all ages & 0 (Ref) & & \\
- 0-14 & 1.861 & 1.844 & 1.878 \\
- 15-64 & -0.657 & -0.674 & -0.641 \\
- 65-74 & -0.882 & -0.899 & -0.866 \\
- 75-84 & -0.853 & -0.87 & -0.836 \\
- 85+ & 0.647 & 0.63 & 0.664 \\
Constant & 1.013 & 0.999 & 1.027 \\
\hline Note. All regression coefficients significantly differ \\
from 0 $(p<0.0001)$.
\end{tabular}




\section{Transition coefficients for computation of weekly SDRs from CDRs}

The transition coefficients $R$ (according to equations (4a) and (4b)) for 36 countries/regions (all countries but Iceland and Luxembourg available in STM F as of 15.12.2020) for all ages combined and for the five aggregated age groups in 2010-2020 are given in Supplementary Annex 2.xlsx.

One should note that the transition coefficients for the most recent years may change in response to updating of STM F and HMD.

\section{Summary}

This paper provides a simple method for the estimation of week-specific standardized death rates when detailed data is not available. The calculation does not require detailed age-specific weekly data but uses data on annual mortality by five-year age group.

Analyses of STM F data from 28 countries/regions for which weekly mortality by 5-year age groups showed that weekly SDRs may be derived from weekly $C D R$ s. The resulting $S D R 1$ values may be considered as a good approximation of the exact standardized death rates $S D R$. The inaccuracy of the estimation tends to be somewhat higher for ages below 15 and above 85 compared to all ages combined and ages 15 to 84 and for males compared to both sexes and females

The method can be applied for estimating SDRs:

- in populations and years for which weekly mortality by 5 -year age groups is not available.

- in small populations with unstable weekly mortality by 5 -year-age groups. In such populations, detailed mortality has to be grouped into broader age categories before analysis.

\section{Supplementary files}

Annex 1. The median, 5th, and 95th percentiles of weekly SDR1/SDR0 ratios by sex for 28 countries and age groups $0-14,15-64,65-74,75-84$, and $85+$ in 2000-2020.

Annex 2. Transition coefficients for the calculation of standardized death rates from crude death rates for 36 countries/regions, all ages combined and age groups 0-14, 15-64, 65-74, 75-84, and 85+in 2010-2020.

\section{References}

Jdanov D.A., Shkolnikov V.M., Alustiza Galarza A. with the assistance of Carl Boe and Magali Barbieri. 2020. Short-Term M ortality Fluctuations Data series (STM F). Last update 26.02.2021. Available at https://www.mortality.org/Public/STM F DOC/STM FNote.pdf

Revision of the European Standard Population Report of Eurostat's task force. 2013 edition. Theme: Population and social conditions. Collection: M ethodologies \& Working papers. Eurostat. European Comission 2013. ISBN 978-92-79-31094-2; ISSN 1977-0375; doi:10.2785/11470; Cat. No: KS-RA-13-028- 
EN-N. https://ec.europa.eu/eurostat/documents/3859598/5926869/KS-RA-13-028-EN.PDF/e713fa79ladd-44e8-b23d-5e8fa09b3f8f

Lee R.D., Carter L.R. 1992. "M odeling and Forecasting U.S. M ortality." Journal of the American Statistical Association 87: 659-675. 